\title{
The rupture of a single liquid aluminium alloy film
}

Cite this: Soft Matter, 2014, 10, 4711

Received 3rd March 2014 Accepted 10th April 2014

DOI: $10.1039 / c 4 s m 00487 f$

www.rsc.org/softmatter

\author{
K. Heim, ${ }^{\text {*a }}$ F. García-Moreno, ${ }^{\text {ab }}$ G. S. Vinod Kumar, ${ }^{\text {ad }}$ A. Rack $^{c}$ and J. Banhart ${ }^{\text {ab }}$
}

The present study is based on the idea of understanding the rupture of films in metal foams by studying free standing metallic films as a model system. Liquid dynamics, the velocity of the rupturing material as well as the behaviour of ceramic particles inside the melt were analysed optically ex situ and by synchrotron X-ray radiography in situ. It was found that the resistance of films to rupture is mainly based on the interaction between solid particles and an immobile oxide skin, the formation of which depends on the oxygen content of the surrounding atmosphere and the presence of magnesium.

\section{Introduction}

Liquid metal foams are dispersions of gas bubbles in a molten metallic alloy and are usually merely seen as precursors of the corresponding solid foams obtained after solidification. As the structure and properties of a solid metallic foam are determined by its liquid predecessor there is interest in understanding the mechanisms of stabilisation and why and under which circumstances instabilities trigger the rupture of films separating adjacent bubbles and therefore coarsen the bubble size distribution. ${ }^{1,2}$ The stability of aqueous foams has been extensively studied and the mechanisms of stabilisation by both surfactants ${ }^{3}$ and particles ${ }^{4}$ have been elucidated. As foams are difficult to investigate due to the complexity of their structure, single films are often used instead as simplified model systems. ${ }^{5}$ This approach is feasible for metallic foams as well. ${ }^{6,7}$ Beside flat single films, artificial plateau borders exhibiting a realistic curvature can be created. ${ }^{8}$ Their stability was shown to depend crucially on the presence of dispersed solid particles and of oxygen in the surrounding atmospheres, on the size of the films and on the velocity of film pulling, which is in accordance with real metal foams. ${ }^{9-11}$ These findings regarding stabilisation in a simplified model system were found to be useful to understand the stability of real metallic foams.

Although aqueous films have been studied for many years, the conditions under which a film becomes unstable and the details of its rupture have been elucidated only in the recent past. ${ }^{12}$ Saulnier $e t$ al. and Savva et al. have studied the retraction velocity of single soap films and compared theoretical and

aInstitute of Applied Materials, Helmholtz Centre Berlin for Materials and Energy, Hahn-Meitner-Platz 1, 14109 Berlin, Germany. E-mail: korbinian.heim@ helmholtz-berlin.de

${ }^{b}$ Institute of Materials Science and Technology, Technical University Berlin, Hardenbergstrasse 36, 10623 Berlin, Germany

'European Synchrotron Radiation Facility, 38043 Grenoble Cedex, France ${ }^{d}$ SRM Research Institute, SRM University, Kattankulathur, 603203, India numerical results of film thinning in the context of viscosity and liquid surface tension..$^{13,14}$

Coming back to metallic systems, coalescence has been studied in liquid metal foams only, mostly by using synchrotron radioscopy. ${ }^{15}$ The rupture of an individual single film within an evolving liquid metal foam was discussed by measuring the velocity of a retreating film, which is a novel insight regarding metal foam stability. ${ }^{16}$ However, different structures in real foams impose a limit to the understanding of the behaviour of its individual elements, e.g. plateau borders or nodes. Therefore, we developed a method to investigate film rupture in analogy to the cited studies on aqueous films by considering individual films, aiming at the extension of our knowledge of metallic films in foams in particular the kinetics of rupture and their stabilisation.

\section{Experimental methods}

The effect of alloying elements in particle-free alloys was investigated by comparing Al99, AlSi9 and AlSi9Mg0.6 alloys (all values in wt\%). The latter alloy was produced by adding $0.6 \mathrm{wt} \% \mathrm{Mg}$ to a commercial AlSi9 alloy in an open resistance furnace at $7500^{\circ} \mathrm{C}$. The behaviour of particle-containing composites was studied by using commercial F3S20S material produced by Alcan, Montreal, Canada. It has the same composition as the particle-free alloy AlSi9Mg0.6 but contains $20 \mathrm{vol} \% \mathrm{SiC}$ particles of mean diameter $10 \mu \mathrm{m}$. To study the influence of the type of solid particles, Al, AlSi9 and AlSi9Mg0.6 alloys were reinforced by 6 vol\% $\mathrm{TiB}_{2}$ particles via flux-assisted in situ synthesis. ${ }^{17}$ The mean particle size of the $\mathrm{TiB}_{2}$ particles lies between $1 \mu \mathrm{m}$ and $3 \mu \mathrm{m}$.

All experiments were carried out in a controlled atmospheric chamber. A constant gas flow of argon or air allowed us to control the level of oxygen and to study its influence on the film stability. The measurement of oxygen content was carried out with an "Oxygen Service Controller II" from Prozess-Informatik GmbH, Germany, with a measurement range from $<1 \mathrm{ppm}$ to $100 \% \mathrm{O}_{2} \cdot{ }^{18}$ After the desired oxygen content of the atmosphere had been reached, the alloy was molten, heated up to $680^{\circ} \mathrm{C}$ and held there. 
To investigate the behaviour of liquid films and their incipient rupture, two different wire frame structures made of $0.4 \mathrm{~mm}$ thick molybdenum wire were prepared, immersed into the melt and pulled out, thereby forming a liquid metallic film.

(i) It is known from previous studies that a circular film of $12 \mathrm{~mm}$ diameter remains liquid for $10 \mathrm{~s}$ after leaving the melt if it gets pulled at $1 \mathrm{~mm} \mathrm{~s}^{-1} \cdot{ }^{18}$ In other words, a film remains liquid in an area of $10 \mathrm{~mm}$ above the melt surface, after leaving the melt at the applied pulling velocity. Thus the usage of a rectangular wire frame structure (RF) of $30 \mathrm{~mm}$ height $(12 \mathrm{~mm}$ width) allows us to study the evolution of a liquid film in situ for at least $30 \mathrm{~s}$ during film pulling, see the dotted frame in Fig. 1a. As the lower part of the frame remains immersed in the melt, heat conduction might even extend the area of the liquid film.

Liquid films were studied as long as they were stable and it was investigated how their rupture is triggered and how the edge of a rupturing film expands. A high-speed camera system (pco.1200 hc, $200 \mathrm{fps}, 1280 \times 1024$ pixel, $5 \times$ magnification) was used. The time evolution of the size of holes in the films was quantified by evaluating binarised images using the software "ImageJ".

(ii) The effect of the presence of a Plateau border on the stability of a liquid film was studied using a thermally coupled quadruple frame (QPF) of two pairs of circular wire frames arranged in parallel, see Fig. 1c. A film is suspended between the upper pair, see Fig. $1 \mathrm{~d}$ and $e,{ }^{8}$ while the lower frame pair was kept in the melt at all times, see Fig. $1 b$ and $c$ to obtain a good thermal flow into the upper frames, thus keeping the film in the liquid state as long as possible. To investigate the film in situ the upper frame pair was pulled out of the melt and stopped at the position of the field of view (FOV), see Fig. 1b. A continuous bridge of liquid was formed along the connecting wires and enabled drainage of liquid from the upper film back to the melt. The lower frames are dummy frames, their circular shape not being mandatory as only the upper frames shape the liquid.

In order to investigate the interior of the collapsing film and to quantify its kinetics, experiments were carried out at beamline ID 19 of the European Synchrotron Radiation Facility. Fast phase contrast X-ray radioscopy allowed us to visualise solid particles and their flow in the liquid metal. A pco.dimax 12 bit and $2016 \times 2016$ pixel camera system was used to record images at $1000 \mathrm{fps}$ within the FOV given by the dotted frame in Fig. $1 \mathrm{~b} .^{19}$

\section{Results}

\section{Healing process of liquid films until rupture}

Liquid films were pulled at a rate of $1 \mathrm{~mm} \mathrm{~s}^{-1}$ using the RF configuration (i), see Fig. 1a, to investigate their behaviour for 30 s. During withdrawal of the film, the occurrence of small translucent areas was frequently observed, which in many cases disappeared shortly after they appeared. This phenomenon, called the "healing process" in the following, is highlighted three times in Fig. 2a by white circles at different positions for an AlSi9Mg0.6/SiC/20p film pulled in air. Following this, see Fig. 2a, lower right, the translucent area was no longer healed but unfolded into full rupture of the film.

Healing could be found for all Mg-containing alloys pulled in air (AlSi9Mg0.6, AlSi9Mg0.6/SiC/10p, AlSi9Mg0.6/SiC/20p and AlSiMg0.6/ $\left.\mathrm{TiB}_{2} / 6 \mathrm{p}\right)$. The moment of rupture or whether a film will rupture at all in an experiment could not be predicted. Films made of AlSiMg0.6/ $\mathrm{TiB}_{2} / 6 \mathrm{p}$ did not rupture in the three experiments performed.

An evaluation of the conditions under which a translucent area triggers rupture cannot be given due to statistical fluctuations and the occasional occurrence of even bigger stable

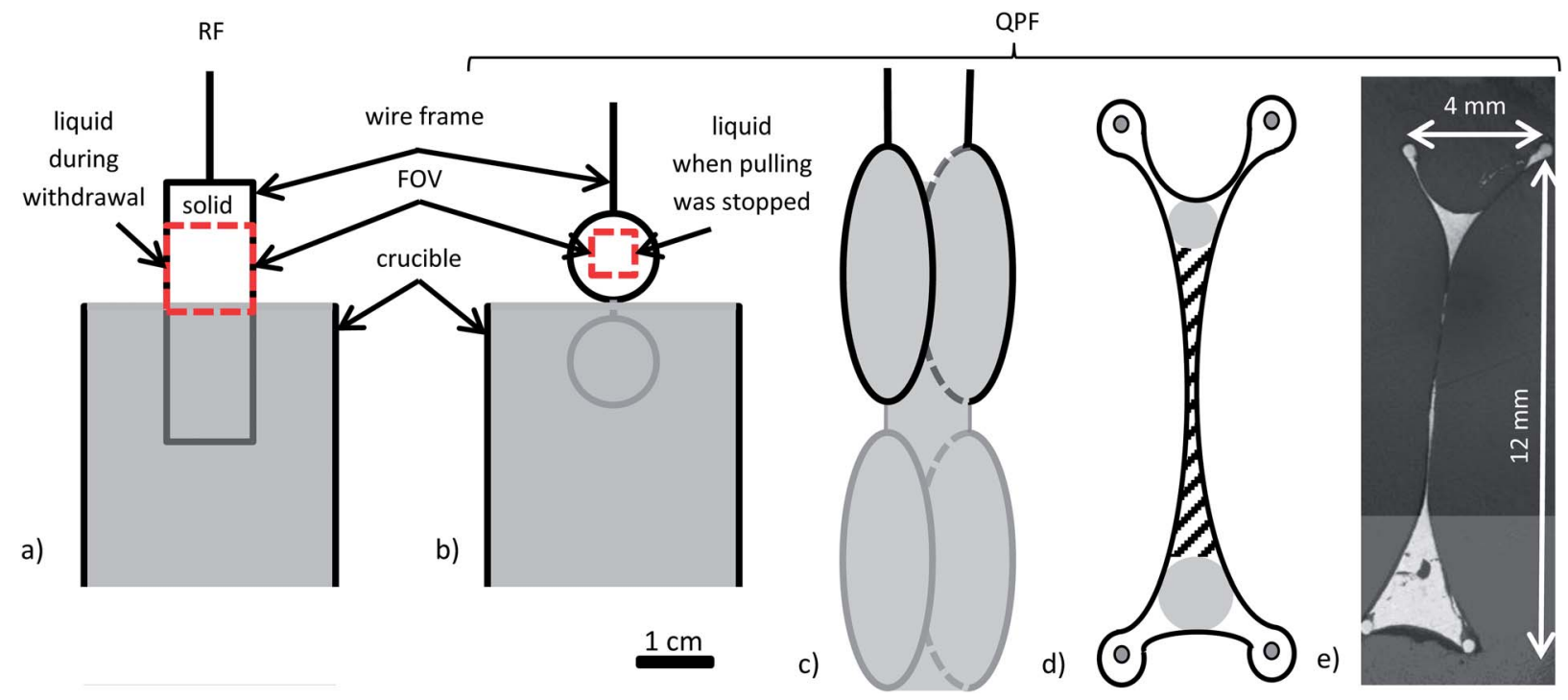

Fig. 1 Schematic of film pulling systems. (a) Rectangular frame (RF); the red dotted frame indicates where the film remains liquid during pulling and where the field of view (FOV) is located approximately. (b) Thermally coupled quadruple wire frame (QPF); the dotted frame indicates the FOV for synchrotron radioscopy. (c) Schematic of QPF configuration in (b). The lower grey frames of (c) are dummy frames. (d and e) Side view of the relevant upper wire frame pair and the corresponding suspended metallic film (schematic and real image after solidification). 


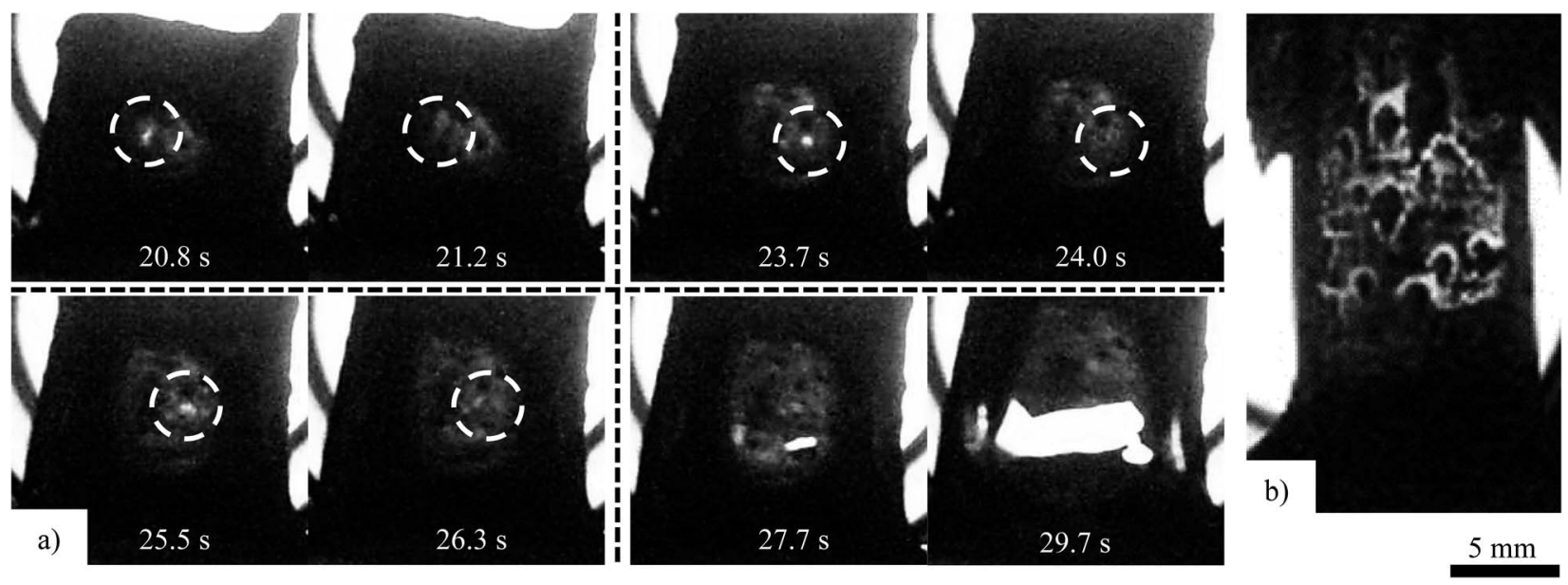

Fig. 2 (a) Light microscopic images of film healing in an AlSi9Mg0.6/SiC/20p film pulled in air. Three events at different positions in the time interval between $20.8 \mathrm{~s}$ and $26.3 \mathrm{~s}$ are shown. Finally, the film ruptures between $27.7 \mathrm{~s}$ and $29.7 \mathrm{~s}$. White circles indicate translucent areas which occur and disappear shortly after. (b) Image of a liquid stabilised film of the same composite and pulled with the RF configuration featuring a large group of translucent areas which did not lead to rupture after their occurrence. Scales for (a) and (b) are the same.

translucent areas. The size of a translucent area which caused the film shown in Fig. 2a to rupture was about $1.5 \mathrm{~mm}^{2}$. However, another film of the same material and pulling conditions, see Fig. 2b, remained stable even after a translucent area of $3 \mathrm{~mm}^{2}$ area had occurred. Thus, a general quantitative criterion for film stability cannot be given in this way. $\mathrm{Al} / \mathrm{TiB}_{2} / 6 \mathrm{p}$ and $\mathrm{AlSi} / \mathrm{TiB}_{2} / 6 \mathrm{p}$ films were not stable at all and ruptured directly after leaving the melt.

When the oxygen level in the atmosphere was reduced from $21 \%$ to $1000-2000 \mathrm{ppm}$, films of AlSi9Mg0.6, AlSi9Mg0.6/SiC/ $10 \mathrm{p}$, AlSi9Mg0.6/SiC/20p occasionally survived temporarily, but ruptured without a visible healing process. The occurrence of only one small translucent area already leads to rupture in such cases.

\section{Velocity of a rupturing film}

As obviously the liquid dynamics during rupture play an important role, the velocity of some rupturing films made using the RF configuration (i), see Fig. 1b, was analysed. As films made of $\mathrm{Al} / \mathrm{TiB}_{2} / 6 \mathrm{p}$ and $\mathrm{AlSi} / \mathrm{TiB}_{2} / 6 \mathrm{p}$ were not stable at all and films made of AlSi9Mg0.6/ $/ \mathrm{TiB}_{2} / 6 \mathrm{p}$ did not rupture in a single case, the focus was put on alloy AlSi9Mg0.6 and its $\mathrm{SiC}$ reinforced version AlSi9Mg0.6/SiC/20p. Films were pulled in air $\left(21 \% \mathrm{O}_{2}\right)$ as well as in a reduced oxygen atmosphere $\left(1000-2000 \mathrm{ppm} \mathrm{O}_{2}\right)$ at a velocity of $1 \mathrm{~mm} \mathrm{~s}^{-1}$. The evolving area of the gap during rupture was determined and a rate calculated by linear fitting. As a result, significant differences for the two applied oxygen levels were found, see Fig. 3. Films pulled and ruptured in a reduced oxygen atmosphere collapse more completely and form a bigger hole than films in air. The rate of gap area change for AlSi9Mg0.6 was $23 \%$ higher for films drawn in 1000-2000 $\mathrm{ppm} \mathrm{O}_{2}\left(1487 \pm 38 \mathrm{~mm}^{2} \mathrm{~s}^{-1}\right)$ than for $21 \% \mathrm{O}_{2}$ $\left(1139 \pm 42 \mathrm{~mm}^{2} \mathrm{~s}^{-1}\right)$. The same was observed for AlSi9Mg0.6/ $\mathrm{SiC} / 20 \mathrm{p}$ where the rate increased by $44 \%$ from $1007 \pm 42 \mathrm{~mm}^{2}$ $\mathrm{s}^{-1}$ at $21 \% \mathrm{O}_{2}$ to $1818 \pm 57 \mathrm{~mm}^{2} \mathrm{~s}^{-1}$ at $1000-2000 \mathrm{ppm} \mathrm{O}_{2}$.

\section{Particle behaviour during rupture}

High-speed synchrotron X-ray radiography providing strong phase contrast unveils how particles act inside films pulled using the QPF configuration (ii). $\mathrm{AlSi} / \mathrm{TiB}_{2} / 6 \mathrm{p}$ films pulled in
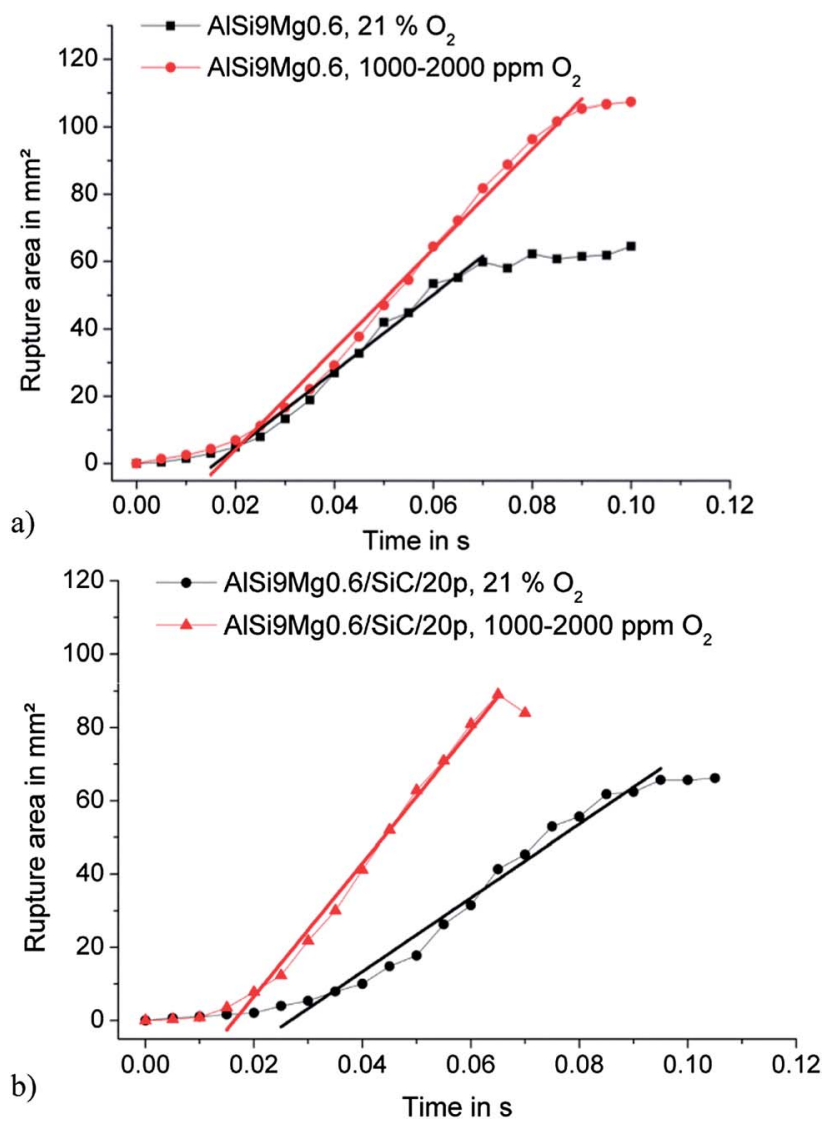

Fig. 3 Evolution of the gap area during rupture of films made of (a) AlSi9Mg0.6 and (b) AlSi9Mg0.6/SiC/20p in both $21 \%$ and 1000-2000 ppm $\mathrm{O}_{2}$ atmospheres using the RF configuration. 
air are known for their low stability. Nevertheless, this instable material shows how a triggered rupture might be stopped from further expanding, see Fig. 4.

The look at a rupture event occurring during withdrawal of a film using synchrotron radioscopy with just $1 \mathrm{~ms}$ exposure time demonstrates that a particle cluster (red circle) next to the incipient rupture was pushed away. In contrast, two other clusters (encircled in white) situated at some distance from the origin of the rupture event did not only not change their position but were even so immobile that they hindered the expanding film from retracting any further. Retraction of the film was brought to end and further movement ceased. The edges of the ruptured film clearly exhibit a wrinkled, folded structure, which indicates that the surface of the film was rigid at some point.

By measuring the area of the incipient rupture within the first 47 images (or $47 \mathrm{~ms}$ ) two stages can be distinguished, see Fig. 5 in which images I-III of Fig. 4 are highlighted. A high rate of gap opening within the first $25 \mathrm{~ms}$ until the film comes into contact with the immobile particle clusters (point I $\rightarrow$ II) and a lower rate after (point II $\rightarrow$ III), during which gap opening is hindered by these clusters and continues only at positions where no clusters are situated.

\section{Discussion}

\section{Healing process}

The experiments using the RF configuration showed the phenomenon of healing, where translucent areas occur and disappear in a liquid film. As even the thinnest layer of metal is opaque in the visible light range these areas must consist of two oxide films which formed the surface layers of the film before the melt retracted. Healing then implies that melt has flowed back into the previously translucent areas. Healing could only be found for films containing $\mathrm{Mg}$ and pulled in air. This can be ascribed to the high oxidation rate of $\mathrm{Al}-\mathrm{Mg}$ alloys, ${ }^{20}$ as it has already been demonstrated for single circular metallic films. ${ }^{18}$ The prerequisite for the possibility of retraction and backflow of melt into a thinned region without rupture seems to be a certain level of oxidation, e.g. expressed by the oxide layer thickness. As the oxidation rate at a lower oxygen content of the atmosphere is also decreased, ${ }^{21}$ the absence of healing in this situation can be explained. The exact conditions under which a translucent spot develops into a rupture cannot be determined and could depend on the extent of local oxidation. Possibly a certain spot size has to be exceeded while the thickness of the oxide (bi)film falls below a certain threshold.

A similar behaviour is already well known for aqueous foams and confirms our interpretation. ${ }^{22,23}$ By reducing the thickness of a single, particle-stabilised aqueous bubble by capillary forces, particles, which have been ordered in layers, will be forced to rearrange successively. If this process is continued, a layer without any particles forms (here $8 \mathrm{~nm}$ in thickness), which is known as a so-called black spot, see Fig. 6 . Such black spots can spontaneously grow and force the film to rupture once they have reached a certain size. This uncontrolled growth process, the unknown critical size of the black spots and the occurrence of an unpredictable collapse of the film, is similar to
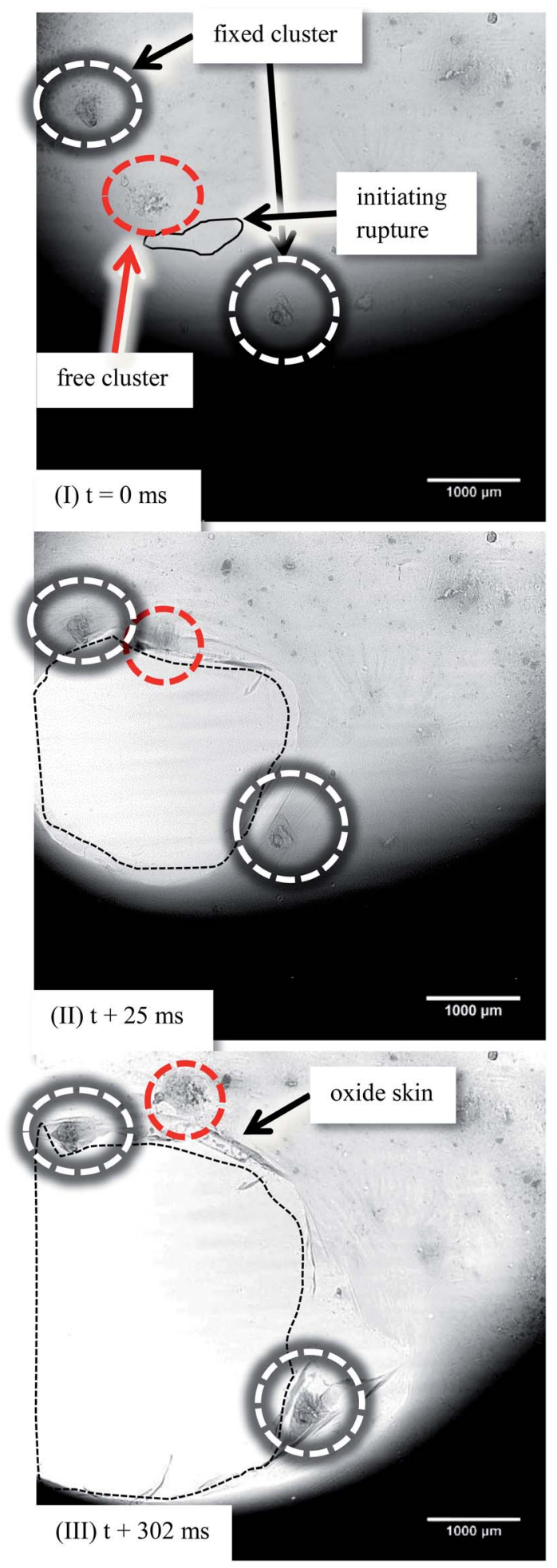

Fig. 4 X-ray radiograms acquired with $1000 \mathrm{fps}$ of three chosen moments of a rupture event of an $\mathrm{AlSi} / \mathrm{TiB}_{2} / 6 \mathrm{p}$ film pulled in air. White circles indicate fixed particle clusters, and red circles indicate the free moveable ones. The solid black freehand contour line at $t=0 \mathrm{~ms}$ marks the incipient rupture. The broken black lines at $t+25$ and $t+302$ ms mark the edge of the expanding gap in the film. 


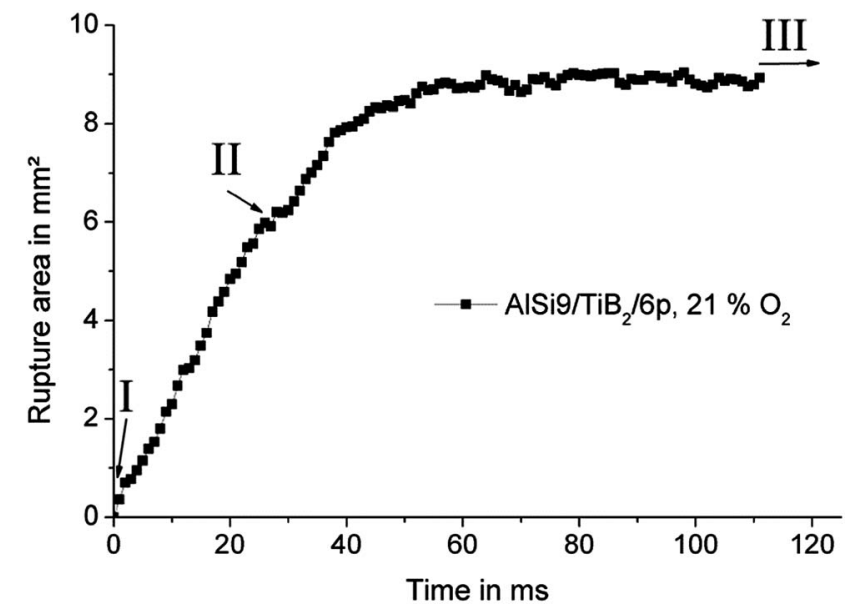

Fig. 5 Evolution of the rupture area of the AlSi9/TiB $2 / 6 p$ film of Fig. 4. Numbers I-III refer to the three images of Fig. 4.

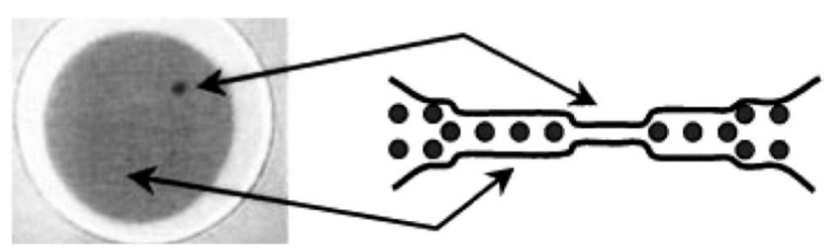

Fig. 6 Successive thinning of a particle-stabilised aqueous film monitored using reflected light. Photograph of a real film (left) and schematic depiction of structural order of particles (right) according to Sethumadhavan et al. ${ }^{23}$

what was found for the healing process of liquid metal films and underpins the analogy to aqueous systems. There are differences, e.g., that ordered arrangements of particles have not been confirmed for metallic films, which is reasonable and can be explained by the absence of electrostatic forces within metals. Moreover, the length scales are different with particles and films in metals being three orders of magnitude larger (20-100 $\mu \mathrm{m}) .{ }^{1}$ However, the general thinning process and the occurrence of particle-free destabilised areas in aqueous films is analogous to the occurrence of translucent areas observed in metallic films.

\section{Rupture velocity}

The velocity of a rupturing film was found to depend on the oxygen level in the atmosphere for both the alloys AlSi9Mg0.6 and AlSi9Mg0.6/SiC/20p. The surface tension $\gamma_{\mathrm{LG}}$ is the driving force to modify the pressure difference $\Delta P$ and thus the capillary suction of melt from the film (with pressure $P_{\mathrm{F}}$ and radius $r_{\mathrm{F}}$ ) into the plateau border (with pressure $P_{\mathrm{PB}}$ and radius $r_{\mathrm{PB}}$ ) as: ${ }^{24}$

$$
\Delta P=P_{\mathrm{PB}}-P_{\mathrm{F}}=\gamma_{\mathrm{LG}}\left(\frac{1}{\gamma_{\mathrm{PB}}}-\frac{1}{\gamma_{\mathrm{F}}}\right)
$$

As the radii will not change due to the fixed wire frame structure used, surface tension will have an influence. By comparing values for pure liquid $\mathrm{Al}$ at $700{ }^{\circ} \mathrm{C}$, the decrease from an unoxidised state, $1050 \mathrm{mN} \mathrm{m}^{-1}$, to an oxidised state, $865 \mathrm{mN} \mathrm{m}^{-1}$, is notable. ${ }^{25}$ Assuming that the difference is comparable for the alloy used in this study, the reduced velocity of a retracting film at $21 \% \mathrm{O}_{2}$ in comparison to $1000-2000 \mathrm{ppm}$ $\mathrm{O}_{2}$ could be at least partially explained, as the surface tension provides the accelerating force that pulls the melt of a film into the delimiting plateau border. Surface tension and velocity should be proportional. As a matter of fact, the velocity decrease by oxidation of rupturing AlSi9Mg0.6 films (-23\%) is in the same order as the reduction of surface tension $(-18 \%)$, see Fig. 3 .

The reason why the film rupture velocity of particle-stabilised films (AlSi9Mg0.6/SiC/20p) is reduced even more compared to their particle-free counterparts $(-44 \%)$ can be explained by considering data related to $\mathrm{Al}-\mathrm{Al}_{2} \mathrm{O}_{3}$ composites. It was found that an increasing volume fraction of particles decreases the surface tension by $\approx 50 \%$ (from $900 \mathrm{mN} \mathrm{m}^{-1}$ at 5 vol\% down to $450 \mathrm{mN} \mathrm{m}^{-1}$ at 10 vol\%). ${ }^{26}$ Therefore, the order of magnitude of the effect expected is correct. Thus, surface tension and capillary suction can be reduced by particles and oxygen independently and therefore the effect of the particle content and atmospheric oxygen content on the velocity of rupturing films is similar.

Additional factors that could influence the velocity of film rupture include (i) the mechanical rigidity of the oxidised surfaces of films pulled in air (slowing down rupture) and (ii) the higher viscosity of the particle-containing melts ${ }^{27}$ (also slowing down rupture). Both effects point in the same direction as the surface tension changes discussed above and cannot be assessed quantitatively.

The rupture velocities in both model systems (RF and QPF) are much slower than the measured velocities of rupturing films inside real metallic foams. García-Moreno et al. have discovered that bubbles of $3 \mathrm{~mm}$ diameter rupture within $\approx 600 \mu \mathrm{s}$ $\left(\approx 5000 \mathrm{~mm} \mathrm{~s}^{-1}\right.$ in comparison to $\approx 20-100 \mathrm{~mm} \mathrm{~s}^{-1}$ for a film of $12 \mathrm{~mm}$ diameter). Possible reasons for these differences include higher capillary forces due to smaller curvatures, the avoidance of surface oxidation (those metallic foams are blown by hydrogen) and internal bubble pressure differences which increase the velocity of the retracting films.

\section{Resistance against rupture}

The resistance of a film against rupture is an essential criterion differentiating between a stable film and its broken equivalent. We found that particles or particle clusters can be fixed in a film and intercept a collapsing film, see Fig. 4. Such particles are therefore pinned to a rigid skin, which becomes visible as a wrinkled and folded structure near the margins of the expanding gap. This skin must be the oxide skin forming at the gas-liquid interface in the presence of oxygen and especially in Mg-containing alloys. This observation is the missing link to understand and describe the healing process as well: small translucent areas, which occur without any particles in their centres, see Fig. 2 and 6, are stabilised by surrounding fixed particles, oxides or pores, see Fig. 3, as long as those can be refilled again with melt by capillary suction before rupture. 


\section{Summary}

- Mg-containing films pulled in air $\left(21 \% \mathrm{O}_{2}\right)$ show the phenomenon of healing: translucent areas consisting of oxide (bi)films only from which the metal has retracted are refilled with the metal and the film remains stable.

- In an ambient atmosphere containing just 1000-2000 ppm $\mathrm{O}_{2}$ films rupture spontaneously and areas devoid of metal are not healed.

- If a film is pulled in air and/or particles are present its rupture is slower. The decreased surface tension can be held responsible for this effect besides the mechanical or rheological properties of the film.

- An interaction of solid particles and an immobile oxide skin is the basis of the resistance to rupture.

\section{Acknowledgements}

We thank the Deutsche Forschungsgemeinschaft (DFG grants GA 1304/2 and BA1170/17) and the European Space Agency (ESA grant AO-99-075) for financial support.

\section{Notes and references}

1 J. Banhart, Adv. Eng. Mater., 2006, 8, 781-794.

2 X. Liu, Y. Li, X. Chen, Y. Liu and X. Fan, J. Mater. Sci., 2010, 45, 6481-6493.

3 C. Hedreul and G. Frens, Colloids Surf., A, 2001, 186, 73-82.

4 R. J. Pugh, Adv. Colloid Interface Sci., 2005, 114-115, 239-251.

5 K. J. Mysels, K. Shinoda and S. Frankel, Soap films: studies of their thinning, Pergamon, New York, 1959.

6 N. Babcsán, D. Leitlmeier, H. P. Degischer and J. Banhart, Adv. Eng. Mater., 2004, 6, 421-428.

7 G. S. Vinod Kumar, F. Garcia-Moreno, N. Babcsán, A. H. Brothers, B. S. Murty and J. Banhart, Phys. Chem. Chem. Phys., 2007, 9, 6415-6425.

8 K. Heim, G. S. Vinod Kumar, F. Garcia-Moreno, I. Manke and J. Banhart, Colloids Surf., A, 2013, 438, 85-92.

9 K. Kadoi and H. Nakae, Mater. Trans., 2011, 52, 1912-1919.

10 S. W. Ip, Y. Wang and J. M. Toguri, Can. Metall. Q., 1999, 38, 81-92.
11 D. Leitlmeier, H. P. Degischer and H. J. Flankl, Adv. Eng. Mater., 2002, 4, 735-740.

12 H. Lhuissier and E. Villermaux, Phys. Rev. Lett., 2009, 103, 0545011-0545014.

13 N. Savva and J. W. M. Bush, J. Fluid Mech., 2009, 626, 211240.

14 L. Saulnier, F. Restagno, J. Delacotte, D. Langevin and E. Rio, Langmuir, 2011, 27, 13406-13409.

15 S. Zabler, A. Rack, F. García-Moreno, A. Ershov, T. Baumbach and J. Banhart, Imaging fast processes in liquid metal foams and semi-solid alloys using synchrotron radioscopy with spatio-temporal micro-resolution, Springer, Berlin, Heidelberg, 2010.

16 F. Garcia-Moreno, A. Rack, L. Helfen, T. Baumbach, S. Zabler, N. Babcsán, J. Banhart, T. Martin, C. Ponchut and M. Di Michiel, Appl. Phys. Lett., 2008, 92, 13410411341043.

17 G. S. Vinod Kumar, N. Babcsán, B. S. Murty and J. Banhart, Verfahren zur Herstellung von Metallschäumen und Metallschaum, German Patent Application DE 102006 031213.9, 2007.

18 Proceedings of the 8th International Conference on Porous Metals and Metallic Foams, Raleigh NC, ed. K. Heim, G. S. Vinod Kumar, F. García-Moreno, J. Banhart and A. Rabiei, USA, 2013, p. 4, in press.

19 A. Rack, F. Garcia-Moreno, C. Schmitt, O. Betz, A. Cecilia, A. Ershov, T. Rack, J. Banhart and S. Zabler, J. X-Ray Sci. Technol., 2010, 18, 429-441.

20 D. L. Belitskus, Oxid. Met., 1971, 3, 313-317.

21 C. Garcia-Cordovilla, E. Louis and A. Pamies, J. Mater. Sci., 1986, 21, 2787-2792.

22 D. T. Wasan, A. D. Nikolov, L. A. Lobo, K. Koczo and D. A. Edwards, Prog. Surf. Sci., 1992, 39, 119-154.

23 G. N. Sethumadhavan, A. D. Nikolov and D. T. Wasan, J. Colloid Interface Sci., 2001, 240, 105-112.

24 R. J. Pugh, Adv. Colloid Interface Sci., 1996, 64, 67-142.

25 L. Goumiri and J. C. Joud, Acta Metall., 1982, 30, 1397-1405.

26 N. Babcsán, D. Leitlmeier and H. P. Degischer, Materialwiss. Werkstofftech., 2003, 34, 22-29.

27 M. Flemings, Metall. Mater. Trans. A, 1991, 22, 957-981. 